The impact of culture and identity on emotional reactions to insults

\author{
Angela T. Maitner \\ American University of Sharjah \\ Diane M. Mackie \\ University of California, Santa Barbara \\ Janet V. T. Pauketat \\ University of California, Santa Barbara
}

Eliot R. Smith

Indiana University

Author Note: Please address correspondence to Angela Maitner, Department of International Studies, American University of Sharjah, P.O. Box 26666, Sharjah, United Arab Emirates; amaitner@aus.edu; Phone: +971 6515 2437, Fax: +971 6515 2516. This research was funded in part by a Faculty Research Grant from the American University of Sharjah awarded to Angela Maitner. Experimental materials and raw data can be made available in accordance with SPSP's Data Sharing Policy. 


\begin{abstract}
People from honor cultures show heightened emotional responses to insults to their social image. The current research investigates whether people from honor cultures also show heightened protection of social identities. We find that honor concerns may be embedded in some social identities but not others, and that those identities associated with honor concerns are defended more than identities not associated with honor. Three experiments investigated participants' emotional responses to insults to their ethnic or student identity. Results showed that compared to dignity culture (British) participants, participants from an honor culture (Arab) reported stronger anger responses both across and within cultures when their Arab identity, an identity explicitly linked to honor concerns, was insulted. In contrast, responses did not differ between dignity (American) and honor (Arab) cultures when participants received an insult to their student identity, a non-honor-oriented identity. These findings suggest that overarching cultural values are not applied to all identities, and therefore, that cultural variables influence psychological outcomes differently for different identities.
\end{abstract}

Keywords: culture, social identity, honor, emotion, insult 


\section{The impact of culture and identity on emotional reactions to insults}

In September 2012, anti-American sentiment flared in response to an amateur video posted on YouTube that depicted the Prophet Muhammad. Although malice was displayed by only a minority of the world's Muslims, news coverage focused on violent protests outside U.S. Embassies (Obeidallah, 2012), prompting the New Yorker to ask "Why is the Arab world so easily offended?” (Ajmani, 2012).

In fact, most people tend to feel angry when they are insulted (Averill, 1983; Bettencourt \& Miller, 1996; Miller, 2001; Rodriguez Mosquera, Manstead, \& Fischer, 2002). However, research investigating cultures of honor suggests that individuals may respond more strongly to insult if they come from a culture where honor concerns are important (Cohen \& Nisbett, 1994; 1997; Cohen, Nisbett, Bowdle, \& Schwarz, 1996; IJzerman, van Dijk, \& Gallucci, 2007). Because groups constitute important aspects of the self (Tajfel \& Turner, 1986), insults to social identities can lead to similar reactions as when the individual him- or herself is offended (Mackie, Devos, \& Smith, 2000). This suggests that individuals from honor cultures may also respond more strongly to insults to their social groups.

This paper investigates how emotional reactions to group-based insults vary by cultural background and social identity, exploring two potential ways that culture and identity may interact to influence emotional reactions. The first possibility is that culture, as an overarching set of values and processes, may influence all identities held by members of a particular culture, and therefore, insults to any identity should be responded to more strongly by members of an honor culture than by members of a dignity culture. The second possibility is that cultural values may link differently to different social identities, in which case members of honor cultures will show heightened emotional reactions only when an honororiented identity is insulted. 


\section{Cultural Orientation}

Individuals from honor cultures have a sense of self-worth that comes from both internal and external sources (Leung \& Cohen, 2011). That is, honor must be both selfasserted and socially ascribed, and the individual does not hold honor without both (see PittRivers, 1966). Because of their strong concern for reputation and integrity, individuals from honor cultures are motivated to defend and protect their social image in the eyes of others (Rodriguez Mosquera, Fischer, Manstead, \& Zaalberg, 2008). Individuals from dignity cultures, on the other hand, have a sense of self-worth that is primarily self-ascribed. Therefore people from dignity cultures are relatively less affected by feedback from others (see Kim, Cohen, and Au, 2010).

Cross et al. (2014) showed that individuals understand the concept of honor differently across cultures, with Turks, members of an honor culture, perceiving honor as prototypically comprising honesty, keeping promises, being trustworthy, having personal values, having dignity, self-respect, and not being hypocritical or stealing. In the Northern United States (a dignity culture), participants perceived honor as prototypically comprising doing the right thing, being respecting and respectful, being trustworthy, honest, having integrity, self-respect, and morals, helping others, having personal values, and being hardworking. Participants in both groups perceived honor as reflective of social status, moral behavior, and self-respect, suggesting that both cultures perceive honor as a form of internal and external valuation reflecting the individuals’ appropriate behavior.

Because honor is more central to self-worth in honor cultures, research shows that people from honor cultures have more extreme reactions to insult than people from dignity cultures (see Cohen \& Nisbett, 1994; 1997; Cohen et al., 1996; IJzerman et al., 2007). Honor demands respect, and thus insults are reacted to strongly in the service of defending one's honor (IJzerman et al., 2007). Individuals who endorse honor norms feel more anger in 
response to insult (IJzerman et al., 2007), and this reaction is accompanied by a spike in testosterone levels (Cohen et al., 1996). Other research has shown that relative to individuals from non-honor cultures, individuals from honor cultures are more likely to confront an oncoming stranger (Cohen et al., 1996), retaliate indirectly (Uskul, Cross, Günsoy, GerçekSwing, Alözkan, \& Ataca, 2015), or condone violence in response to an insult, especially when that insult involves a false accusation (Cohen \& Nisbett, 1994; Cross, Uskul, GerçekSwing, Alözkan, \& Ataca, 2013). Likewise, they are less likely to yield in the face of interpersonal conflict (Günsoy, Cross, Uskul, Adams, \& Gercek-Swing, 2015). Research also shows heightened shame reactions to being judged negatively by others in honor cultures, at least when honor issues are at stake (Rodriguez Mosquera et al., 2002).

Even absent insult, research shows that both anger and shame are afforded in honor cultures (Boiger, Güngör, Karasawa, \& Mesquita, 2014). Whereas anger may motivate the target to claim or reclaim honor, shame reflects a publically tarnished image, indicating that honor has been lost in the eyes of others.

Overall, research suggests that individuals who come from honor cultures will react more strongly to insults that threaten their social image than will individuals from dignity cultures. However, most anthropological and social psychological work investigating honor has defined and explored it as a value associated with the individual or family. Recent research, however, showed that honor endorsement was associated with national identification in Americans (Barnes, Brown, Lenes, Bosson, \& Carvallo, 2014). National identification, in turn, was associated with the personalization of threats and subsequent defensive reactions to illegal immigration and terrorism. That is, the more individuals endorsed honor values, the more strongly they identified with their nationality, and the more defensive they were of the group. Other research showed that group honor concerns (a combination of the desire to maintain both family and national honor) for Arabs were 
associated with support for violence against Americans, due to increased perceptions of disrespect and mistreatment of Arabs (Levin, Roccas, Sidanius, \& Pratto, 2015). Thus, it seems likely that individuals can perceive threats to the social image of their social identities, and that doing so can lead to aggressive intergroup consequences, similar to those seen at the interpersonal level.

However, honor may not be a value that is associated with all social identities. Foundational to Self-Categorization Theory is the idea that different norms and values are associated with different social identities (Turner, Hogg, Oakes, Reicher, \& Wetherell, 1987). Indeed, Verkuyten and Pouliasi (2006) reported that bicultural Greeks living in the Netherlands reported higher concerns with family integrity ${ }^{1}$ when their Greek, as opposed to their Dutch, identity was activated, showing that values can shift along with changes to one’s activated cultural identity. Moreover, Barnes et al. (2014) argue that honor is most likely to be associated with identities that can provide an individual with strength and protection against rivals, which historically promoted the formation of clans or tribes. They suggest that in the context of international conflict, honor endorsement may promote identification with strong nations. Thus, honor endorsement (typically high within honor cultures) may promote identification with tribal and/or strong groups which protect the individual against perceived conflict. In other words, even within an honor culture system, this research suggests that some identities might be more associated with honor than others.

\section{Intergroup Emotions Theory}

Intergroup Emotions Theory (Mackie et al., 2000; Mackie, Maitner, \& Smith, 2015; Mackie \& Smith, 2015; Mackie, Smith, \& Ray, 2008; Smith, 1993) argues that when a specific group membership is made salient, individuals perceive events through a group lens, assessing the goals, motives, and resources the group has in relation to a given social context (e.g., Hastorf \& Cantril, 1954). Group-level appraisals incite group-level emotions and group- 
level action tendencies (see Doosje, Branscombe, Spears, \& Manstead 1998, Gordijn, Yzerbyt, Wigboldus, \& Dumont, 2006; Mackie et al., 2000; Smith, Seger \& Mackie, 2007). Research shows that, in general, individuals feel anger when they perceive their group has been intentionally and unfairly slighted (e.g., Gordijn, Wigboldus \& Yzerbyt, 2001; Kessler \& Hollbach, 2005; Mackie et al. 2000; Yzerbyt, Dumont, Wigboldus, \& Gordijn, 2003). Shame likewise has been shown to reflect a threat to the social image of the group (Maitner, 2015), or to result when negative ingroup behaviors reflect poorly on the group’s identity (Lickel, Schmader, Curtis, Scarnier, \& Ames, 2005). We suggest that if the worth of a specific identity is defined by honor, individuals may interpret an insult directed against that identity as especially threatening. If honor is not associated with a particular group membership (such as when the sense of worth is considered inalienable), individuals will still detect a threat, but they will be less concerned with the implications of the threat for their social value and will respond with correspondingly less intense anger and little or no shame.

\section{Current Research}

In this research, we investigate reactions to insults with Arab students at an Americanstyle, English-language institution in the United Arab Emirates, as well as with British and American university students. Whereas Arab culture has been historically described as an honor culture (see Dodd, 1973; Levin et al., 2015), British and American culture have been labeled as dignity cultures (see Leung \& Cohen, 2011; although Barnes et al., 2014, would suggest that individuals could still show honor endorsement within these cultures, and that doing so may be associated with higher group identification). We pit the hypothesis that culture influences all identities that exist within a cultural system equally against the hypothesis that cultural values may be differentially linked to different identities. If culture influences all identities equally, then we would expect Arab students, members of an honor culture, to respond more emotionally to insults than British and American students. If honor 
is differentially linked to different identities, in contrast, we would expect Arab students will react differently to insults to different identities, showing heightened reactions to insults to their Arab, but not student identity.

\section{Study 1}

In Study 1, Arab and British participants read an identical insult to their group, then reported how they appraised the insult, how it made them feel, and what they wanted to do. We investigated whether Arabs, members of an honor culture, responded more strongly to insulting feedback compared to British, members of a dignity culture. Following Barnes et al. (2014), we also predicted that honor-endorsement would inspire higher levels of identification with the group.

\section{Method}

\section{Participants}

Participants were 100 students who were approached on their campus. Fifty Arab students were recruited from the American University of Sharjah (AUS) ${ }^{2}$, an Americancurriculum university in the United Arab Emirates (33 female, 17 male), and 50 British students were recruited from the University of Kent, a British-style University in England (24 female, 25 male, 1 unreported). Questionnaires were stacked in a random order so that participants could be randomly assigned to either a control or insult condition.

\section{Procedure}

Participants were approached in both locations during the summer by the same female, American experimenter. They were asked to complete a short questionnaire that explored intergroup perceptions. No incentive was offered for participation. Participants who agreed to participate were given a consent form, followed by a three page questionnaire.

Insult manipulation. Participants were told that a number of visitors to their country had written short reflections about their stay and that they would be asked to read one such 
paragraph. Arab students read a paragraph about the target's stay in the UAE, and British students read the same paragraph about the same target's stay in the UK. All participants learned that the visitor was an American who was having his/her first experience in the country. The visitor had found the country unique and the architecture impressive. However the visitor also expressed some challenges. In the control condition, the visitor said "I've had very few interactions with Arab/British people. It's been difficult to meet anyone who lives here, as people seem busy and occupied throughout the day, so I haven't had the opportunity to form a clear impression of Arab/British people.” In the insult condition, the target said "I've found Arab/British people to be quite rude and unhelpful. It's been difficult to actually meet anyone who lives here, as people seem annoyed when I ask for directions or advice, so I have formed a pretty negative impression of Arab/British people.” This insult specifically implicated honor concerns by suggesting violations in honor norms of politeness and hospitality (see Cohen \& Vandello, 2004), and represented socially inappropriate or disrespectful behavior (see Cross et al., 2014).

\section{Dependent variables.}

Manipulation Checks. To verify that they perceived the insult as an affront to the groups' social image (i.e., the group was disrespected by others) which is a precondition for amplified anger responses in honor cultures, participants first reported the extent to which they believed the visitor felt respect and understanding for Arabs/British people ( $r=.43$ for Arabs, $r=.54$ for British; participants also reported the extent to which the visitor felt contempt and disgust; 1=Not at all, 6=Very much). Participants then evaluated how harmful and just the visitor's impression was (1=Strongly Disagree, 6=Strongly Agree; The visitor's opinion is harmful/damaging/a threat/harmless (reverse coded) to Arabs/British people; $\alpha=.80$ for Arabs, $\alpha=.87$ for British; The visitor's opinion is justified/legitimate/fair/reasonable; $\alpha=.86$ for Arabs, $\alpha=.88$ for British). 
Emotional reactions and behavioral intentions. Next, participants reported how the visitor's impression made them feel. We measured one emotion previously identified as being afforded in honor cultures, which was the extent to which participants felt anger (angry, annoyed, offended, $\alpha=.77$ for Arabs, $\alpha=.75$ for British) toward the visitor. We also measured a second emotion which may be afforded in honor cultures, which is the extent to which participants felt respect (satisfied, pleased, respect, understanding, $\alpha=.83$ for Arabs, $\alpha=.87$ for British) toward the visitor. Because honor has to be socially conferred, it is possible that one way to respond when one's honor has been questioned is to reciprocally disrespect a target. Finally, we measured anxiety (anxious, worried, $r=.25$ for Arabs, $r=.13$ for British), which is not expected to be afforded in honor cultures, because it does not promote behavior which defends or protects one's social image, nor does It reflect acknowledgement that the image has been damaged. Thus, we expected cultural differences in felt anger and respect, but not in anxiety.

Participants next reported behavioral intentions, including desires to oppose ${ }^{3}$ or avoid the visitor (ignore, avoid, $r=.52$ for Arabs, $r=.73$ for British; all variables, $1=$ Not at all, 6=Very much).

Honor and identification. Participants then reported the extent to which they valued honor using five items from Rodriguez Mosquera et al. (2008; for example, "What others think of my family is important to me;” 1=Not at all important, 6=Extremely important, $\alpha=.68$ for Arabs, $\alpha=.83$ for British). Finally, participants reported private regard for (e.g., "I feel good about being Arab/British;” $\alpha=.86$ for Arabs, $\alpha=.91$ for British) and identification with their group (e.g., "Being Arab/British is an important reflection of who I am;” $\alpha=.82$ for Arabs, $\alpha=.85$ for British) using the corresponding subscales from Luhtanen and Crocker's (1992) Collective Self-Esteem scale (1=Strongly Disagree and 6=Strongly Agree).

Participants reported demographic information before being thanked and debriefed. 


\section{Results}

\section{Manipulation Checks}

Descriptive statistics for all dependent variables by culture and insult condition can be seen in Table 1. Analysis revealed that both Arab and British participants perceived less respect in the insult condition $(M=2.48, S D=0.96)$ than the control condition $(M=3.60, S D$ $=1.12), F(1,95)=27.95, p<.001, \eta_{\mathrm{p}}^{2}=.227$. Perceived respect was not affected by Culture $\left(p=.448, \eta_{\mathrm{p}}^{2}=.006\right)$ or the Culture $\times$ Insult interaction $\left(p=.857, \eta_{\mathrm{p}}^{2}<.001\right)$.

Both Arab and British participants also found insulting feedback to be more harmful $(M=3.30, S D=0.92)$ than the neutral feedback in the control condition $(M=2.13, S D=$

0.89), $F(1,96)=41.14, p<.001, \eta_{\mathrm{p}}{ }^{2}=.300$. Perceptions of harm were unaffected by Culture $\left(p=.142, \eta_{\mathrm{p}}^{2}=.022\right)$ or the Culture $\times$ Insult interaction $\left(p=.436, \eta_{\mathrm{p}}^{2}=.006\right)$.

Arab and British perceptions of justice, however, were affected by Culture, $F(1,96)$ $=8.71, p=.004, \eta_{\mathrm{p}}^{2}=.083$, Insult $F(1,96)=17.16, p<.001, \eta_{\mathrm{p}}{ }^{2}=.152$, and the Culture $\times$ Insult interaction $F(1,96)=8.21, p=.005, \eta_{\mathrm{p}}{ }^{2}=.079$. Arab participants found the opinion expressed in the insult condition to be significantly less just than the opinion expressed in the control condition, $p<.001, \eta_{\mathrm{p}}{ }^{2}=.204$. British participants, in contrast, found the opinion expressed in both conditions to be equally just, $p=.369, \eta_{\mathrm{p}}^{2}=.008$.

Overall, both Arab and British participants found the insulting feedback to convey a lack of respect and to be harmful to their group, meeting the preconditions necessary to evoke honor concerns and suggesting that the insult was, indeed, insulting. Notably, only Arab participants labelled insulting feedback as unfair.

\section{Cultural Differences in Honor and Identification}

As expected, Arab participants $(M=5.30, S D=.79)$ reported significantly higher honor concerns than British participants $\left(M=4.37, S D=.97 ; F(1,96)=27.93, p<.001, \eta_{\mathrm{p}}{ }^{2}\right.$ $=.225) \cdot{ }^{4}$ Analysis also yielded a marginal main effect of the insult manipulation, $F(1,96)=$ 
2.81, $p=.097, \eta_{\mathrm{p}}{ }^{2}=.028$. Participants in the control condition reported marginally higher honor concerns $(M=4.98, S D=.93)$ than participants in the insult condition $(M=4.69, S D=$ 1.05). These main effects were not qualified by an interaction $\left(p=.464, \eta_{\mathrm{p}}{ }^{2}=.006\right)$.

Arab participants also reported higher private regard $(M=5.14, S D=1.07)$ and identification $(M=4.10, S D=1.22)$ than British participants (private regard $M=4.44, S D=$ 1.12, $F(1,95)=10.18, p=.002, \eta_{\mathrm{p}}{ }^{2}=.097$; identification $M=3.28, S D=1.23, F(1,95)=$ 10.87, $\left.p=.001, \eta_{\mathrm{p}}^{2}=.103\right)$. These effects were not impacted by the insult manipulation (private regard: $p=.333, \eta_{\mathrm{p}}{ }^{2}=.010$; identification: $p=.188, \eta_{\mathrm{p}}{ }^{2}=.018$ ) or the Culture $\times$ Insult interaction (private regard: $p=.127, \eta_{\mathrm{p}}{ }^{2}=.024$; identification: $p=.289, \eta_{\mathrm{p}}{ }^{2}=.012$ ).

Across cultures, honor concerns were correlated with both private regard $(r=.40, p<$ $.001)$ and identification $(r=.47, p<.001)$. Thus, similar to Barnes et al. (2014), honor endorsement promoted identification with the participants’ ethnic or national group.

\section{Emotional Reactions}

Thus far, results indicate that across cultures, insulting feedback was considered insulting. Moreover, Arab participants' reported higher concern for honor than did British participants. To investigate whether this cultural difference in concerns for honor influenced emotional reactions, we conducted Culture $\times$ Insult ANOVAs on reported emotions.

Participants' anger was affected by Culture, $F(1,96)=13.16, p<.001, \eta_{\mathrm{p}}^{2}=.121$, Insult $F(1,96)=31.70, p<.001, \eta_{\mathrm{p}}^{2}=.248$, and the Culture $\times$ Insult interaction $F(1,96)=$ 6.71, $p=.011, \eta_{\mathrm{p}}{ }^{2}=.065$. Both Arab $\left(p<.001, \eta_{\mathrm{p}}{ }^{2}=.260\right)$ and British participants $(p=.034$, $\eta_{\mathrm{p}}{ }^{2}=.046$ ) felt significantly angrier after being insulted than after receiving neutral feedback. Importantly, however, Arab participants felt significantly angrier in response to the insult than did British participants, $p<.001, \eta_{\mathrm{p}}{ }^{2}=.168$. Arab and British participants did not differ from one another in the control condition, $p=.465, \eta_{\mathrm{p}}{ }^{2}=.006$. Thus although the insult made 
both groups angry, the members of an honor culture responded with more anger than did members of a dignity culture. ${ }^{5}$

Respect felt for the visitor was also affected by Culture, $F(1,95)=4.27, p=.042, \eta_{\mathrm{p}}{ }^{2}$ $=.043$, Insult $F(1,95)=4.76, p=.032, \eta_{\mathrm{p}}{ }^{2}=.048$, and the Culture $\times$ Insult interaction $F(1$, $95)=5.43, p=.022, \eta_{\mathrm{p}}{ }^{2}=.054$. This was primarily because Arab participants reported feeling more respect for the visitor in the control condition than both British participants in the control condition $p=.003, \eta_{\mathrm{p}}^{2}=.091$ and Arab participants in the insult condition $p=$ $.002, \eta_{\mathrm{p}}{ }^{2}=.096$. Looked at differently, Arab participants reported less respect for the insulting than the neutral visitor, whereas British participants’ already marginal feelings of respect for the target were not affected by feedback $\left(p=.916, \eta_{\mathrm{p}}{ }^{2}<.001\right)$.

Analysis also revealed a main effect of Insult on anxiety, $F(1,95)=5.74, p=.018$, $\eta_{\mathrm{p}}{ }^{2}=.057$ such that participants reported more anxiety in the insult $(M=2.79, S D=1.06)$ than in the control condition $(M=2.31, S D=0.88)$. There were no effects of Culture or the Culture $\times$ Insult interaction (both $p s>.118, \eta_{\mathrm{p}}{ }^{2}<.026$ ). Thus it appears that culture only moderated emotional reactions that were indicative of honor concerns and the protection of the social image.

\section{Behavioral Intentions}

Participants' desire to oppose the visitor was affected by Culture, $F(1,95)=8.70, p=$ $.004, \eta_{\mathrm{p}}{ }^{2}=.084$, Insult $F(1,95)=5.73, p=.019, \eta_{\mathrm{p}}{ }^{2}=.057$, and the Culture $\times$ Insult interaction, $F(1,95)=5.14, p=.026, \eta_{\mathrm{p}}{ }^{2}=.051$. Simple effects tests revealed that Arab participants reported a stronger desire to oppose the visitor when they received insulting than neutral feedback $\left(p=.001, \eta_{\mathrm{p}}{ }^{2}=.102\right)$. Moreover, Arab participants reported a stronger desire to oppose the insulting visitor than did British participants $\left(p<.001, \eta_{\mathrm{p}}^{2}=.126\right)$, although they did not differ from British participants in their desire to oppose the neutral 
visitor $\left(p=.632, \eta_{\mathrm{p}}^{2}=.002\right)$. Finally, British participants reported no stronger desire to oppose the insulting visitor than the neutral visitor $\left(p=.928, \eta_{\mathrm{p}}{ }^{2}=.000\right)$.

In contrast, participants’ desires to avoid the visitor were affected by Insult, $F(1,95)$ $=7.91, p=.006, \eta_{\mathrm{p}}{ }^{2}=.077$, but not by Culture or the Culture $\times$ Insult interaction (both $p s>$ $\left..362, \eta_{\mathrm{p}}^{2}<.009\right)$. Across cultures, participants reported a stronger desire to avoid the insulting visitor $(M=1.86, S D=0.95)$ than the neutral visitor $(M=1.39, S D=0.69) .{ }^{6}$

\section{Discussion}

In this study, Arab participants reported higher honor concerns than did British participants. Although Arab and British participants evaluated an insult as equally disrespectful and harmful, Arab participants perceived the insult to be more unfair and reported more anger than British participants exposed to the same insult. Arab participants also reported less respect for the visitor after insult, whereas British participants' feelings of respect for the visitor were unaffected by insult. Finally, Arab participants reported a stronger desire to respond aggressively to insult than did British participants.

Across cultures, the perception of being respected is considered prototypically central to the concept of honor (see Cross et al., 2014). Consistent with this idea, our results show that although both Arab and British participants perceive a lack of respect from insulting feedback, that perception translated more strongly into emotion (anger and reciprocated lack of respect) for Arab participants, who represent an honor culture.

Although these results show that members of an honor culture reacted more strongly to an insult to a national or ethnic identity, it remains possible that they will not show heightened protection of all social identities. Thus in a second study, we investigated Arab and American students' responses to an insult to their student identity, which we chose as an identity that would be less likely to be linked to honor concerns than national or ethnic identity. 
Barnes and colleagues (2014) argued that honor would likely be associated with identities that could be invoked as a way of gaining strength for confronting conflict. We suggest that the student identity may not be strong enough to provide such a protective function. Moreover, because we conducted research with Arab participants at the American University of Sharjah, an American-style liberal arts institution, it is possible that many of the norms and values associated with that identity are reflective of more dignity-centric ideals. In fact, American university settings have been described as individualistic (see Stephens, Fryberg, Markus, Johnson, \& Covarrubias, 2012), and likewise Kenyan university students reported self-concepts that were substantially more individualistic than other urban or rural Kenyans (Ma \& Schoeneman, 1997), further suggesting that an alternative cultural system may be linked to the student identity. If this is indeed the case, and if only honor-related identities provoke strong reactions to insults, then Arab students, even as members of an honor culture, would be unlikely to show heightened protection of their student identity

\section{Study 2}

In Study 2, Arab and American students read one of two insulting letters about students' role in creating academic integrity problems or a neutral letter on the same topic, then reported appraisals and emotional reactions. We expected that participants from both cultures would evaluate insults negatively and feel anger as a result. However, to investigate the impact of culture on reactions and to create multiple opportunities for Arab students to show heightened protection of their student identity, we manipulated the nature of the two insults. One insult directly and explicitly implicated honor, whereas the other implicated dignity. Importantly, if cultural values are infused into all social identities, then we would expect Arab participants to report more anger in response to insults than Americans, and more shame as a reflection of their tarnished image. These heightened reactions would be especially likely when honor values were directly implicated, whereas they may be dampened 
when dignity was implicated. On the other hand, if the student identity is not infused with honor values, then we would expect Arabs to respond similarly to Americans, even when an insult directly implicated honor.

\section{Method}

\section{Participants}

Participants were 244 students who were recruited from psychology courses for partial course credit. One-hundred twenty-seven Arab students were recruited from AUS (84 female, 43 male) and 117 American students from University of California, Santa Barbara (UCSB; 81 female, 32 male, 4 unknown). ${ }^{7}$ Participants were randomly assigned to one of two insult conditions or a control condition.

\section{Procedure}

We attempted to maximize similarity in the procedure across data collection sites, with small differences reflective of the laboratory space available and experimental software employed in the respective laboratories. Participants from UCSB completed the study in separate cubicles on computers running the experiment on Qualtrics software (Qualtrics, 2009). Participants from AUS completed the study in an open computer laboratory in groups of up to eight students on computers running the experiment using MediaLab (Jarvis, 2012).

Students at AUS were separated by a minimum of one empty computer, with small barriers to help maintain privacy. Participants at both locations were asked to read and evaluate a letter ostensibly written by faculty members from their university discussing problems with academic honesty on their campus.

Insult manipulation. Participants in the control condition read a letter beginning “Academic integrity has become one of the largest challenges facing [university]. The number of students who obtain papers and assignments from external sources, or use technology or other means to cheat on tests is astounding. A recent report circulated to the 
administration estimated that the percentage of students cheating on some aspect of work that contributed to their grade had increased to more than $75 \%$ and that almost all students had witnessed some form of cheating during their time at [university]. Given that learning is the true purpose of educational institutions, finding ways to ensure the honesty of work that students submit is critical, and all [university] students play a role in undermining that honesty whether they cheat themselves or condone it in others.”

Participants in the honor insult condition received the additional sentence “[University] students are clearly to blame-they demonstrate complete disrespect for authority and institution, and their behavior is an appalling reflection of their lack of personal and family honor.” This insult was created to directly and explicitly implicate honor concerns by employing the words "honor” and “disrespect”, and by implicating students' inappropriate and dishonest behavior. Participants in the dignity insult condition received the additional sentence "[University] students are clearly to blame-they demonstrate complete lack of responsibility for themselves and their futures, and their behavior is an appalling reflection of students, in general, lack of integrity.”

We predicted that if Arab students associated honor with their student identity as an overarching cultural orientation, they would show first, a stronger anger response to the honor than the dignity insult, and second, a stronger emotional reaction to the honor insult than would American students. If Arab students did not associate honor norms with their student identity, on the other hand, we expected them to show equal anger responses across insult, and to show similar emotional reactions to their American counterparts.

\section{Dependent variables.}

Emotional reactions. Participants reported how the letter made them feel, including the extent to which they felt anger (angry, annoyed, offended, outraged, $\alpha=.87$ for Arabs, $\alpha=.79$ for Americans), and respect (respect, admiration, $r=.42$ for Arabs, $r=.73$ for 
Americans) as in Study 1. In this study, to more completely investigate whether participants perceived an insult to tarnish the reputation of their group, we also included a measure of shame (shame, embarrassment, $r=.67$ for Arabs, $r=.63$ for Americans; $1=$ Not at all, and 7=Extremely).

Manipulation Checks. As in Study 1, participants next evaluated how harmful (The faculty's opinions are harmful/damaging; $r=.67$ for Arabs, $r=.74$ for Americans) and just (The faculty's opinions are just/fair; $r=.62$ for Arabs, $r=.76$ for Americans) the impression was using a Likert-scale anchored at 1=Strongly Disagree, 7=Strongly Agree. Participants then reported the extent to which faculty seemed to feel respect (respect, understanding, $r=.47$ for Arabs, $r=.80$ for Americans) for students, using a scale labeled 1=Not at all, and $7=$ Extremely ${ }^{8}$

Identification. Participants reported identification with their university using 10-items from Roccas, Savig, Schwartz, Halevy, and Eidelson (2008) (e.g., "I feel strongly affiliated with [university] students;” $\alpha=.90$ for Arabs, $\alpha=.92$ for Americans) before reporting demographic information and being thanked and debriefed.

\section{Results}

\section{Manipulation Checks}

Means and standard deviations of all dependent variables by culture and insult condition can be seen in Table 2. Analysis of participants' perceptions of respect conveyed by faculty revealed a main effect of insult condition, $F(2,236)=6.39, p=.002, \eta_{\mathrm{p}}{ }^{2}=.051$. Least significant differences post-hoc tests revealed that both Arab and American participants perceived both insult conditions as less respectful (Honor Insult: $M=2.99, S D=1.40$, Dignity Insult: $M=3.41, S D=1.54$; these conditions were marginally different from one another, $p=.063)$ than the control condition $(M=3.86, S D=1.33$, compared to insult conditions, both $p s<.046)$. Perceptions of respect were also marginally affected by Culture 
$\left(F(1,236)=2.99, p=.085, \eta_{\mathrm{p}}^{2}=.013\right)$, with Arabs perceiving marginally more respect $(M=$ 3.57, $S D=1.48)$ than Americans $(M=3.26, S D=1.44)$. There was no impact of the Culture $\times$ Insult interaction $\left(p=.537, \eta_{\mathrm{p}}{ }^{2}=.005\right)$. Across cultures then, when faculty added either of two insults to their general statement about academic integrity, the resulting letter was perceived as significantly less respectful than the neutral letter.

Just as they found the insulting faculty letters to be disrespectful, both Arab and American students found the insults to be harmful (Honor Insult: $M=4.00, S D=1.47$; Dignity Insult: $M=3.63, S D=1.45$, these means are not different, $p=.115$ ) compared to the control condition $(M=3.16, S D=1.46$, compared to insult conditions, both $p s<.040), F(1$, 236) $=6.13, p=.003, \eta_{\mathrm{p}}{ }^{2}=.049$. These results were not affected by Culture $\left(p=.850, \eta_{\mathrm{p}}{ }^{2}<\right.$ $.001)$ or the Culture $\times$ Insult interaction $\left(p=.844, \eta_{\mathrm{p}}{ }^{2}=.001\right)$.

Likewise, Arab and American students’ perceptions of justice were impacted by Insult $F(2,235)=6.75, p=.001, \eta_{\mathrm{p}}^{2}=.054$, but not by Culture $\left(p=.741, \eta_{\mathrm{p}}{ }^{2}<.001\right)$ or the Culture $\times$ Insult interaction $\left(p=.549, \eta_{\mathrm{p}}{ }^{2}=.005\right)$. Students found the opinion expressed in the insult conditions to be significantly less just (Honor Insult: $M=4.29, S D=1.35$, Dignity Insult: $M$ $=4.59, S D=1.45$; these means do not differ $p=.169$ ) than the opinion expressed in the control condition $(M=5.12, S D=1.32$, compared to insult conditions, both $p s<.014)$.

Overall then, participants' perceptions and appraisals of insult to a student identity did not dramatically differ by culture, nor did they differentiate between two different insults. Participants did, however, evaluate insulting feedback as less respectful, more harmful, and less just than a non-insulting evaluation. In other words, the insult manipulations were successful in eliciting appraisals that could motivate defense of one’s social image if, indeed, Arab participants infuse their student identity with honor concerns. 


\section{Cultural Differences in Identification}

Analysis of identification scores yielded no effects of Culture, Insult, or the Culture $\times$ Insult conditions (all $p>.256, \eta_{\mathrm{p}}{ }^{2}<.011$ ). Overall, participants reported relatively high identification with their group $M=5.18, S D=1.06$.

Taken together with the pretested honor results ${ }^{(7)}$, these results suggest that although Arab participants have stronger honor concerns than American participants, they do not have stronger ties to their insulted student identity. Moreover, in contrast to the correlation of honor concerns with ethnic/national identity found in Study 1, Arab participants’ honor concerns in this study were unrelated to student identification, $r=-.03, p=.784^{(8)}$, providing further support for the idea that honor concerns do not inspire increased identification with the student identity. In other words, across cultures, the student identity does not seem to be associated with general honor concerns.

\section{Emotional Reactions}

In this study, participants' anger was affected by Insult $F(2,236)=6.80, p=.001$, $\eta_{\mathrm{p}}^{2}=.055$, but not by Culture $\left(p=.365, \eta_{\mathrm{p}}^{2}=.002\right)$ or the Culture $\times$ Insult interaction $(p=$ .789, $\left.\eta_{\mathrm{p}}{ }^{2}=.007\right)$. Both Arab and American students felt significantly angrier after being insulted (Honor Insult: $M=4.41, S D=1.48$, Dignity Insult: $M=3.94, S D=1.44 ; p=.117$ ) than after receiving neutral feedback $(M=3.41, S D=1.49$, both $p s<.018)$.

Both Arab and American participants also felt less respect for faculty in the insult conditions (Honor Insult: $M=2.90, S D=1.51$, Dignity Insult: $M=2.77, S D=1.64, p=.569$ ) than the control condition $(M=3.45, S D=1.38$, both $p s<.025), F(2,233)=4.49, p=.012$, $\eta_{\mathrm{p}}{ }^{2}=.037$. Respect was also affected by Culture $\left(F(1,233)=14.29, p<.001, \eta_{\mathrm{p}}{ }^{2}=.058\right)$, with Arabs reporting more respect overall $(M=3.38, S D=1.51)$ than Americans $(M=2.63$, $S D=1.49)$. There was no impact of the Culture $\times$ Insult interaction $\left(p=.565, \eta_{\mathrm{p}}^{2}=.005\right)$. 
Reported feelings of shame were not affected by Insult $\left(p=.813, \eta_{\mathrm{p}}{ }^{2}=.002\right)$, Culture $\left(p=.845, \eta_{\mathrm{p}}^{2}<.001\right)$, or the Culture $\times$ Insult interaction $\left(p=.730, \eta_{\mathrm{p}}{ }^{2}=.003\right)$, suggesting that participants were not concerned by insulting evaluations of their social image.

\section{Discussion}

In this study, both Arab and American students evaluated insults to their student identity as disrespectful, harmful, and unfair, relative to more neutral feedback. These insults also made both Arab and American students feel angrier and less respectful toward the faculty authors of the letter. However unlike in Study 1, members of an honor culture did not respond more extremely, even to an insult that directly implicated honor. Additionally, and similar to American participants, Arab students reported little shame in reaction to having their reputation threatened, further supporting the argument that the student identity is less honor imbued.

Thus when the student identity was activated, we found no evidence across two different insults, even when measuring emotions specifically tied to honor concerns, that participants from different cultures responded differently to the same insult. If participants' honor had been at stake, we predicted that they would have been more sensitive to the potential attempt to tarnish their group’s social image, and thus (1) Arab participants would have responded more strongly to insults than American participants, and (2) Arab participants would have responded more strongly to insults targeting honor concerns than non-honororiented insults. However Arab participants’ responses to an honor insult were not substantially different from their responses to a dignity-based insult, or from the responses of American students, members of a prototypical dignity culture.

In fact, we found no evidence of culture impacting appraisals of harm or justice, or feelings of anger or shame. Analysis revealed effects sizes of Culture and the Culture $\times$ Insult interaction on these variables to be near zero. This cannot be attributed either to a lack of 
statistical power or a failure of participants to engage with the material, for we simultaneously observed effects of Insult which were generally 7-10 times stronger. In other words, our null results are reasonably interpretable as indicating the absence of cross-cultural differences in responding. Arab participants did perceive that they were more respected by faculty and felt more respect for faculty overall, but these effects were not moderated by insult condition. Arab participants reported less respect for faculty in response to insulting as compared to less insulting feedback similarly to the American sample.

Although members of an honor culture responded with more anger on behalf of their ethnic identity in response to insult in Study 1, heightened anger responses were not observed from members of an honor culture when their student identity was insulted in Study 2. Such findings are consistent with the hypothesis that not all identities are associated with the same cultural values. Indeed, Arab participants’ identification with their student group was unrelated to their general honor concerns in Study $2^{(8)}$, whereas their ethnic identification was strongly related to honor concerns in Study 1.

\section{Study 3}

In Study 3, we investigated the link between honor and identity directly, and examined how Arab students responded to an insult to their apparently honor-related Arab identity or their apparently non-honor-related student identity. Holding insult (and therefore its potential to evoke honor concerns) constant, Study 3 investigated (1) whether honor values are attached to the Arab and student identity, and (2) whether participants are more emotionally responsive to threats to identities that are more concerned with honor. To investigate more fully whether honor is differentially ascribed to the two identities, we also manipulated whether the insult was made publically or privately.

We predicted that overall, participants would report more anger when an honororiented identity was insulted, reflecting a motivated defense of the internally derived sense 
of self that has been externally affronted. Being disrespected implicates honor, and thus we predicted that participants would show heightened anger reactions any time an honor-oriented identity was insulted. In other words, we expected that participants would report more anger when their Arab identity was insulted than when their student identity was.

However we predicted that shame responses would be impacted by the public vs. private nature of the insult when an honor-oriented identity was threatened, as shame may be more reflective of the externally-ascribed element of honor which is only lost when other people know about the stain to the individual or groups’ image (see Günsoy, Cross, Saribay, Olcaysoy Ökten, \& Kurutaş, 2015 for other ways people mask transgressions from the public eye). Thus, if the student identity was insulted, we predicted low levels of shame overall, because as a low-honor identity, it should be impervious to insult. If the Arab identity was threatened, on the other hand, we predicted stronger shame reactions to public insults which are more likely to tarnish the reputation of the group (and thereby threaten the external component of honor), than to private insults, which leave the social image of the group intact.

\section{Method}

\section{Participants}

Participants were 253 Arab students who were recruited from psychology courses at AUS for partial course credit (177 female, 76 male). ${ }^{9}$ Participants were randomly assigned to the cells of a 2 (Identity: Arab vs. student) $\times 2$ (Insult: public vs. private) between-subjects design. They completed the study in the research laboratory in groups of up to eight students on computers running MediaLab software (Jarvis, 2012).

\section{Procedure}

Participants were asked to read and evaluate an article ostensibly taken from a local news source describing the outcome of an international conference on the Global University. 
Four participants spent less than 4 seconds reading the article, and were therefore excluded from all further analyses as they likely remained unexposed to the manipulations.

Manipulations of insult and identity. Participants in all conditions read an article giving relatively mundane details about a conference that took place in China and was ostensibly attended by university stakeholders (students, faculty, and administrators) from around the world and then learned that "some controversy surrounds the event.” In the private insult condition, the article was ostensibly taken from a university blog which had 1 social media share and reported that "A report from the conference organizers shared privately with local participants...” whereas in the public condition the article ostensibly came from a local, but internationally accessible, newspaper, had 92 social media shares, and read: “A report from the conference released to international news organizations ....”

The article then went on to insult either a high honor (Arab) or low honor identity (student), stating that the report "praised the important contributions from Faculty and Administration, but ranked the contribution of the student delegation as substantially below expectations" or "praised the contribution from Western and East Asian delegates but ranked the contribution of the Arab delegation as substantially below expectations.” This insult placed the participants' groups as somehow below other groups, implicating the concern for status and social image that is prevalent in honor cultures.

\section{Dependent variables.}

Emotional reactions. Participants were asked to share their responses to the article, reporting to what extent, as an Arab/student, the report made them feel anger (angry, annoyed, $r=.68$ ), respect (respect for the conference organizers, admiration for the conference organizers, satisfied, pleased, $\alpha=.80$ ), and shame (shamed, humiliated, $r=.69$ ), $1=$ Not at all, and 7=Extremely. To help mask hypotheses, participants were also asked to report pride (pride, honored, $r=.70$ ), and anxiety (anxious, worried, $r=.60$ ). 
Perceptions and appraisals of insult. Participants next evaluated how harmful (The organizer's report is harmful/damaging; $r=.58$ ), just (The organizer’s report is just/fair; $r=.69$ ), and respectful (The organizer's report show respect/understanding, $r=.72$ ) the report was (1=Strongly Disagree, $7=$ =Strongly Agree). Because participants were insulted in all conditions in this study, we did not expect differences between conditions on these variables.

Behavioral intentions. Participants then reported their desires to write a comment in defense of students (Arabs), criticize the report, confront the conference organizers, or shame the conference organizers (1=Not at all, 7=Very much). These four items were analyzed independently.

Manipulation check. Participants also reported how many people they thought would find out about the report ("Lots of people around the world are likely to find out about this report”, "Only the people participating in the conference are likely to find out about this report” (reverse coded), $r=.49$ ).

Participants also reported an additional and direct appraisal of insult by reporting how insulting the report was ("the report is insulting", "the report is offensive”, $r=.82 ; 1=$ Not at all, 7=Extremely for both measures).

Honor and identification. Participants then reported the extent to which they endorsed honor norms as associated with their activated social identity using the same five items of Rodriguez-Mosquera's measure used in Study 1, modified to reflect the activated identity (i.e. "What others think of Arabs is important to me.") combined with three items from Henry’s (2009) honor measure (i.e. “If someone insults or disrespects Arabs, they will pay.”). The resulting 8-item scale had high reliability for both the Arab $(\alpha=.85)$ and student $(\alpha=.84)$ identity. Participants next reported their group identification using eight items from Roccas et al. (2008) (Arab identification $\alpha=.89$, student identification $\alpha=.86$ ). All participants then completed the honor scale for the non-activated identity and identification with the non- 
activated identity so that we could compare honor and identification with the two groups within-subjects. Finally, participants reported demographic information before being thanked and debriefed.

\section{Results}

\section{Manipulation Check}

Descriptive statistics for the main dependent variables can be seen in Table 3. Participants' evaluation of how public the insult was likely to be made was subjected to an Insult $\times$ Identity ANOVA. Results indicated only a main effect of Insult, $F(1,242)=15.38$, $p<.001, \eta_{\mathrm{p}}{ }^{2}=.060$, with participants expecting the public insult $(M=4.45, S D=1.29)$ to have wider reach than the private insult $(M=3.77, S D=1.41)$. There was no effect of Identity, $F(1,242)=2.05, p=.154, \eta_{\mathrm{p}}^{2}=.008$, or the Identity $\times$ Insult interaction, $F(1,242)$ $=0.85, p=.358, \eta_{\mathrm{p}}^{2}=.003$.

\section{Perceptions and Appraisals of Insult}

Participants' appraisals of the report as being harmful (all $p>.407, \eta_{\mathrm{p}}{ }^{2}<.003$ ), just (all $p>.211, \eta_{\mathrm{p}}{ }^{2}<.006$ ), and respectful (all $p>.12, \eta_{\mathrm{p}}{ }^{2}<.010$ ) were unaffected by whether the insult was made publically or privately, to either the Arab or student identity. As in Studies 1 and 2 where insults were perceived similarly across cultures, in this study, insults were perceived similarly across groups.

Participants' evaluation of the level of insult conveyed, however, was affected by Identity, $F(1,244)=8.68, p=.004, \eta_{\mathrm{p}}{ }^{2}=.034$, but not by Insult $F(1,244)=1.32, p=.252$, $\eta_{\mathrm{p}}{ }^{2}=.005$ or the Identity $\times$ Insult interaction, $F(1,244)=1.61, p=.206, \eta_{\mathrm{p}}{ }^{2}=.007$. Participants reported more insult to their $\operatorname{Arab}(M=3.94, S D=1.33)$, than student identity $(M$ $=3.43, S D=1.39)$. Thus, participants perceived a greater insult to their honor-oriented Arab identity despite the fact that the insult was evaluated as equally harmful, just, and respectful 
as an insult to another identity. This suggests that cultural values may play a role above and beyond objective evaluations in determining how insulting negative feedback is perceived.

\section{Honor and Identification}

Participant-reported honor concerns were submitted to an Insult $\times$ Identity (Arab vs. student identity insulted) $\times$ Group (Arab vs. student honor measured) mixed-model ANOVA with repeated-measures on the final factor. Analysis revealed a significant main effect of Identity, $F(1,243)=114.14, p<.001, \eta_{\mathrm{p}}^{2}=.320$. Consistent with hypotheses, participants reported significantly higher honor concerns for their Arab $(M=5.04, S D=1.09)$ than student $(M=4.35, S D=1.04)$ identities. Analysis also revealed an Identity $\times$ Insult interaction, $F(1,243)=5.61, p=.019, \eta_{\mathrm{p}}^{2}=.023$. Participants reported lower honor concerns for their Arab identity after it had been insulted $(M=4.89, S D=1.09)$ compared to participants whose student identity had been insulted $(M=5.19, S D=1.07), p=.029, \eta_{\mathrm{p}}^{2}=$ .020. In contrast, participants reported equal honor concerns for their student identity, regardless of which identity had been insulted, $p=.979, \eta_{\mathrm{p}}{ }^{2}<.001$. No other effects were significant (all $\left.p>.209, \eta_{\mathrm{p}}{ }^{2}<.006\right)$.

An insult to the Arab identity appears to have resulted in a suppression of selfreported honor concerns. When an honor identity was insulted, perhaps in an ironic attempt to protect the group's social image, Arab participants conveyed that they are not susceptible to insults to their identity. In contrast, reports of student honor concerns were unaffected by insult. We consider this finding further in the discussion.

Identification scores were also submitted to an Insult $\times$ Identity $\times$ Group mixed-model ANOVA. Analysis yielded only a main effect of identity, with Arab students reporting higher identification with their Arab $(M=5.26, S D=0.97)$ than with their student identity $(M=$ 4.86, $\left.S D=0.94), F(1,245)=33.90, p<.001, \eta_{\mathrm{p}}{ }^{2}=.122\right)$. No other effects were significant (all $\left.p>.189, \eta_{\mathrm{p}}^{2}<.007\right)$. 
Correlational analyses revealed that Arab honor was strongly linked to Arab identification $(r=.73, p<.001)$, likewise student honor was linked to student identification ( $r$ $=.61, p<.001)$. Whereas generalized honor concerns were related to Arab identification (Study 1) but not student identification (Study 2), specified honor concerns associated with particular social identities are related to attachment to those groups. That is, the more individuals conferred honor on a particular identity, the more they identified with it.

\section{Emotional Reactions}

Participants’ emotional reactions were subjected to individual Insult $\times$ Identity ANOVAs. Analysis of anger revealed only the predicted main effect of Identity $(F(1,244)=$ 29.46, $\left.p<.001, \eta_{\mathrm{p}}{ }^{2}=.108\right)$, with no effect of Insult $F(1,244)=0.32, p=.572, \eta_{\mathrm{p}}{ }^{2}=.001$ or the Identity $\times$ Insult interaction, $F(1,244)=0.24, p=.627, \eta_{\mathrm{p}}{ }^{2}=.001$. Consistent with hypotheses, participants were significantly angrier when their Arab $(M=3.60, S D=1.64)$ than when their student identity $(M=2.52, S D=1.49)$ was insulted. Reflecting a defense of their internally derived sense of worth, participants reported more anger any time an honororiented identity was insulted.

Analysis of shame responses revealed a main effect of Identity $(F(1,244)=13.60, p$ $\left.<.001, \eta_{\mathrm{p}}^{2}=.053\right)$, qualified by the predicted Insult $\times$ Identity interaction $(F(1,244)=4.82$, $\left.p<.029, \eta_{\mathrm{p}}^{2}=.019\right)$. The main effect of Insult was not significant, $F(1,244)=0.56, p=$ $.453, \eta_{\mathrm{p}}{ }^{2}=.002$. Overall participants reported more shame when their Arab $(M=3.29, S D=$ 1.64) than when their student identity $(M=2.54, S D=1.54)$ was insulted. However, consistent with the Arab identity being honor-oriented, simple main effects tests showed that when their Arab identity was insulted, participants felt more shame when the insult was made publically than when it was made privately $\left(p=.038, \eta_{\mathrm{p}}{ }^{2}=.018\right)$. In contrast, when participants’ student identity was insulted, they felt equal amounts of shame regardless of whether the insult was made publically or privately $\left(p=.310, \eta_{\mathrm{p}}{ }^{2}=.004\right)$. Given that shame 
is an emotion reflective of a tarnished identity (when one is concerned with social image), these results further support the argument that the Arab identity is more honor-oriented than the student identity.

Participants' anxiety was also impacted by main effects of both Identity $(F(1,244)=$ 9.88, $\left.p=.002, \eta_{\mathrm{p}}{ }^{2}=.039\right)$ and Insult $\left(F(1,244)=4.69, p=.031, \eta_{\mathrm{p}}{ }^{2}=.019\right)$. The interaction was not significant $\left(F(1,244)=0.85, p=.357, \eta_{\mathrm{p}}{ }^{2}=.003\right)$. Participants reported more anxiety when their $\operatorname{Arab}(M=3.45, S D=1.55)$ than when their student identity $(M=2.82$, $S D=1.55)$ was insulted, and when the insult was made publically $(M=3.36, S D=1.67)$ compared to when it was made privately $(M=2.91, S D=1.46)$. There were no significant effects on reports of pride or respect (all $p<.161, \eta_{\mathrm{p}}{ }^{2}>.008$ ). Thus again, honor concerns most directly impact those emotions associated with concern for image and reputation. Unlike Study 1, we did not find that felt respect was influenced by which group was insulted, and thus it remains unclear whether this emotion is one which is promoted in honor cultures or within honor identities.

\section{Behavioral Intentions}

There were no main or interactive effects of Identity and Insult on participants’ desires to write a social media comment criticizing or shaming the conference organizers (all $p<.124, \eta_{\mathrm{p}}{ }^{2}>$.010). There was, however, a marginal main effect of Identity on participants desires to confront the conference organizers, $F(1,242)=3.33, p=.069, \eta_{\mathrm{p}}{ }^{2}=.014$. There were no effects of Insult or the Identity $\times$ Insult interaction (both $p>.505, \eta_{\mathrm{p}}{ }^{2}<.002$ ) on confrontation. Overall participants were more motivated to confront the conference organizers when they insulted their Arab identity $(M=3.40, S D=1.65)$ than when they insulted their student identity $(M=3.10, S D=1.71)$. Likewise, there was a main effect of Identity on participants' desires to write a comment defending their group, $F(1,243)=4.45$, $p=.036, \eta_{\mathrm{p}}{ }^{2}=.018$, but no effects of Insult or the Identity $\times$ Insult interaction on desires to 
defend the group (both $p>.576, \eta_{\mathrm{p}}{ }^{2}<.001$ ). Participants reported stronger desires to defend their Arab $(M=4.14, S D=1.95)$ than their student identity $(M=3.63, S D=1.88)$. Thus, participants were more strongly motivated to respond defensively and confrontationally when their honor-oriented Arab identity, compared to when their less honor-oriented student identity, was insulted.

\section{Discussion}

In this study, participants from an honor culture evaluated an insult to their Arab identity as significantly more insulting, despite perceiving it as equally disrespectful, harmful, and unjust as an identical insult to their student identity. Participants felt angrier in response to an insult to their Arab identity. They also reported more shame when their Arab identity was insulted, but only when the insult caused public damage to their reputation. Thus, as expected, participants were more protective of their Arab identity than their student identity. This difference appeared to be due to the fact that participants reported more honor concerns and higher attachment to their Arab than their student identity.

However participants also showed an intriguing bias in the extent to which they attributed honor to each identity. Participants attributed equal honor concerns to their student identity whether or not it had been insulted, showing to some extent, that values associated with the student ingroup are unaffected by insult. In contrast, they reported significantly lower honor concerns associated with their Arab identity if it had been insulted, despite the fact that they showed stronger emotional reactivity to insults to this group. We suggest that the changes in the way honor concerns were reported by condition may reflect a form of identity performance. Klein, Spears, and Reicher (2007) argued that group members may refrain from displaying their endorsement of values associated with the ingroup stereotype, especially when those values are perceived negatively by a salient outgroup. Group members may also downplay certain aspects of a group identity to gain the trust of an outgroup or for 
fear of the outgroup's evaluation of the ingroup. Thus in the (psychological) presence of a global outgroup publically insulting the ingroup, participants may modify their endorsement of honor concerns to gain trust and support or simply to ensure that the ingroup is not perceived as any worse, in line with the negative stereotype conveyed in our opening example. This strategy may be particularly important when individuals care about the social image of their groups.

If this is indeed the case, then one inherent challenge in measuring responses associated with honor is that if individuals are motivated to protect their social image in the moment that they are completing a scale, then they may engage in self-presentational strategies that ironically mask that exact concern. Finding clear emotional reactivity (across Studies 1 and 3), despite changes in the way participants report their honor concerns suggests that honor was indeed implicated in our studies. However, it also points out challenges to measuring a defensiveness-oriented construct using self-report in the face of social identity threat, and points to the need to measure such constructs in independent, non-threatening contexts.

\section{General Discussion}

This research suggests that honor concerns may heighten reactions to insults to particular social identities, but not all identities, even in an honor culture. Study 1 showed that participants from an honor culture responded more strongly to insults to their ethnic identity than did participants from a dignity culture. However, Study 2 showed that participants from an honor culture responded equally to insults to their student identity compared to participants from a dignity culture. Finally, Study 3 showed that participants from an honor culture responded more strongly to insults to their ethnic (honor-oriented) as compared to their student (non honor-oriented) identity, showing predicted changes in emotional reactions when the insult was able to threaten the reputation of the group. 
Thus, we show that honor is not a value that is conferred to all identities equally. Just as Intergroup Emotions Theory argues that emotions are attached to specific identities, here we show that honor is attached to specific identities and different identities have higher or lower concerns with honor. That is, some identities derive self-worth (or identity worth) from internal and external feedback, whereas others are internally derived. It seems that the extent to which particular identities are associated with honor determines how strongly they will be defended and protected.

What influences whether or not particular identities are associated with honor concerns? One possibility, as Barnes et al. (2014) suggested, is that honor becomes associated with identities that provide an individual with strength and protection against rivals. Historically this meant tribal and family identities but now may include national identities as well. However protection against rivals may be valuable only in situations or contexts where such protection is needed - that is, in competitive environments without strong rule of law. In the international community, where, for example, laws are less stable and effective, identifying with one's ethnicity or the Arab league may increase the relative strength of individual Arab nations, and thus the Arab identity may be important to protect. In less competitive environments, such as university settings where grades are not zero-sum, protection against rivals may not be necessary, and thus it may not be as important to protect a reputation of strength and integrity.

A second set of possibilities focus on the centrality of the identity to an individual's sense of self as well as how distinguishing or long-lasting the identity is for the individual. Identities that are unimportant, non-distinctive, or transient may be less important to socially protect, as insults to those identities may not be able to impact the individuals' overall reputation. In the current work, similar to Barnes et al. (2014), we show that identity centrality (group identification) is indeed associated with honor endorsement. 
A final possibility is that the extent to which particular identities have socially ascribed norms of behavior influences whether or not social image becomes important to protect. In honor cultures, for example, there are clear, socially evaluated codes of behavior associated with gender. Thus in honor cultures, gender-based honor is important to protect. In contrast, gender is not as closely associated with proscribed behavior in dignity cultures, and so gender-based honor is not as important to protect in those cultures.

With these factors in mind, we might predict that identities such as religion, occupation, race, sports-team affiliation, and family ties will become associated with honor if they (1) exist in a competitive environment; (2) are centrally important to the individual; (3) are distinguishing; (4) are permanent; or (5) have socially agreed upon and enforced behavioral norms associated with them. The Muslim identity, for example, may be one which is important, distinguishing, permanent, and associated with a clear set of behavioral expectations and rituals, and is thus likely to be another identity associated with honor. In fact it was insults to this identity that were highlighted in the opening example, although the media categorized protesters differently.

In addition to showing that honor values can be applied differently to different identities, this work suggests generalizability of Intergroup Emotions Theory beyond the well-studied Western, individualistic context. Although honor concerns exacerbated appraisals and emotional reactions to insult, we did not otherwise observe fundamental differences in emotional processes. Insults to social identities elicited anger in three countries in line with general expectations. Importantly, this work shows how values associated with different social identities may influence appraisal and emotion processes, and therefore suggests that understanding the connection between identity and cultural value-orientations may be critical to predicting intergroup emotional responses. 
One possible alternative explanation for the findings for studies 1 and 2 is that cultural differences emerge when an insult comes from an outgroup member but not when it comes from an ingroup member. That is, Arab participants may have been more reactive to an insult from an American visitor (a clear outgroup member), than from faculty at their university (who constitute superordinate ingroup members). It is possible that in Study 2, Arab students showed no stronger anger responses than American students because they did not perceive a threat to their reputation when insult was conveyed by members of the (superordinate) ingroup. However, and in line with self-categorization theory, we argue that because we activated the student identity, and not the university identity, faculty members should be seen as an outgroup. Moreover, in Study 3, an insult to both the Arab and student identities comes from international conference organizers - a clear outgroup to both identities. Thus it seems unlikely that differences in emotional responses to insult across the two identities are reflective of who conveyed the insult, but instead reflect different motives to defend and protect the image of the group.

Nguyen and Benet-Martinez (2007) suggest that exposure to multiple cultural contexts, including professional, geographic, and generational cultures, could be associated with bicultural-oriented outcomes, including frame switching among different cultural identities. We likewise suggest that activation of ethnic vs. student identities can elicit different culturally-bounded psychological outcomes, even in individuals not traditionally recognized as bicultural. In an increasingly multicultural world, everyone may be in some way bicultural, switching between and among different cultural orientations associated with different social identities.

Thus, we argue that identity is not only embedded within culture, but that culture is also embedded within identity. As people are exposed to different cultural value systems in different aspects of their daily lives, they may develop identities that endorse perhaps even 
conflicting values, leading to remarkably different psychological outcomes depending upon which identity has been activated. Understanding the links between cultural orientations and social identities may be crucial to furthering our comprehension of how intergroup insults incite emotional reactions and intergroup behaviors. 


\section{References}

Ajami, F. (2012, September 14). Why is the Arab world so easily offended? Washington Post. Retrieved 12-02-13 from http:/www.washingtonpost.com/opinions/in-the-arabworld-why-a-movie-trailer-can-lead-to-violencewhy-cant-the-arab-world-acceptoffenses-without-violence/2012/09/14/d2b65d2e-fdc8-11e1-8adc499661afe377_story_2.html

Averill, J. R. (1983). Studies on anger and aggression: Implications for theories of emotion. American Psychologist, 38, 1145-1160. doi: 10.1037/0003-066X.38.11.1145

Barnes, C. D., Brown, R. P., Lenes, J., Bosson, J., \& Carvallo, M. (2014). My country, my self: Honor, identity, and defensive responses to national threats. Self and Identity, 13, 638-662. doi: 10.1080/15298868.2014.892529

Bettencourt, B. A. \& Miller, N. (1996). Gender differences in aggression as a function of provocation: A meta-analysis. Psychological Bulletin, 119, 422-447. doi: 10.1037/0033-2909.119.3.422

Boiger, M., Güngör, D., Karasawa, M., \& Mesquita, B. (2014). Defending honour, keeping face: Interpersonal affordances of anger and shame in Turkey and Japan. Cognition and Emotion, 28, 1255-1269. doi: 10.1080/02699931.2014.881324

Cohen, D., \& Nisbett, R. E. (1994). Self-protection and the culture of honor: Explaining southern violence. Personality and Social Psychology Bulletin, 20, 551-567. doi: $10.1177 / 0146167294205012$

Cohen, D. \& Nisbett, R. E. (1997). Field experiments examining the culture of honor: The role of institutions in perpetuating norms about violence. Personality and Social Psychology Bulletin, 23, 1188-1199. doi: 10.1177/01461672972311006 
Cohen, D., Nisbett, R. E., Bowdell, B. F. \& Schwarz, N. (1996). Insult, aggression, and the southern culture of honor: An “experimental ethnography.” Journal of Personality and Social Psychology, 70, 945-960. doi: 10.1037/0022-3514.70.5.945

Cohen, D., \& Vandello, J. (2004). The paradox of politeness. In M. Anderson (Ed.), Cultural shaping of violence: Victimization, escalation, response (pp. 119-132). West Lafayette, IN: Purdue University Press.

Cross, S. E., Uskul, A. K., Gerçek-Swing, B., Alözkan, C. \& Ataca, B. (2013). Confrontation versus withdrawal: Cultural differences in responses to threats to honor. Group Processes \& Intergroup Relations, 16, 345-362. doi: 10.1177/1368430212461962

Cross, S. E., Uskul, A. K., Gerçek-Swing, B., Sunbay, Z., Alözkan, C., Günsoy, C., Ataca, B., \& Karakitapoğlu-Aygün, Z. (2014) Cultural prototypes and dimensions of honor. Personality and Social Psychology Bulletin, 40, 232-249. doi: $10.1177 / 0146167213510323$

Dodd, P. C. (1973). Family honor and the forces of change in Arab society. International Journal of Middle East Studies, 4, 40-54. Retrieved 12-03-13 from http://www.jstor.org/stable/162224

Doosje, B., Branscombe, N. R., Spears, R, \& Manstead, A. S. R. (1998). Guilty by association: When one's group has a negative history. Journal of Personality and Social Psychology, 75, 872-886. doi: 10.1037/0022-3514.75.4.872

Gordijn, E. H., Wigboldus, D., \& Yzerbyt, V. (2001). Emotional consequences of categorizing victims of negative outgroup behavior as ingroup or outgroup. Group Processes \& Intergroup Relations, 4, 317-326. doi: 10.1177/1368430201004004002

Gordijn, E., H., Yzerbyt, V., Wigboldus, D., \& Dumont, M. (2006). Emotional reactions to harmful intergroup behavior. European Journal of Social Psychology, 36, 15-30. doi: 10.1002/ejsp.296 
Günsoy, C., Cross, S. E., Saribay, A., Olcaysoy Ökten, I., \& Kurutaş, M. (2015). Would you post that picture and let your dad see it? Culture, honor, and Facebook. European Journal of Social Psychology, 45, 323-335. doi: 10.1002/ejsp.2041

Günsoy, C., Cross, S. E., Uskul, A. K., Adams, G., \& Gercek-Swing, B. (2015). Avoid or fight back? Cultural differences in responses to conflict and the role of collectivism, honor, and enemy perception. Journal of Cross-Cultural Psychology, 46, 1081-1102. doi: 10.1177/0022022115594252

Hastorf, A. H., \& Cantril, H. (1954). They saw a game; a case study. The Journal of Abnormal and Social Psychology, 49, 129-134. doi: 10.1037/h0057880

Henry, P. J. (2009). Low-status compensation: A theory for understanding the role of status in cultures of honor. Journal of Personality and Social Psychology, 97, 451-466. doi: 10.1037/a0015476

IJzerman, H., van Dijk, W. W., \& Gallucci, M. (2007). A bumpy train ride: A field experiment on insult, honor, and emotional reactions. Emotion, 7, 869-875. doi: 10.1037/1528-3542.7.4.869

Jarvis, B. G. (2012). MediaLab (Version 2012.4.120) [Computer Software]. New York, NY: Empirisoft Corporation.

Kessler, T. \& Hollbach, S. (2005). Group-based emotions as determinants of ingroup identification. Journal of Experimental Social Psychology, 41, 677-685. doi:10.1016/j.jesp.2005.01.001

Kim, Y.-H., Cohen, D., and Au, W.-T. (2010). The jury and abjury of my peers: The self in face and dignity cultures. Journal of Personality and Social Psychology, 98, 904-916. doi: 10.1037/a0017936 
Klein, O., Spears, R., \& Reicher, S. (2007). Social identity performance: Expending the strategic side of SIDE. Personality and Social Psychology Review, 11, 28-45. doi: $10.1177 / 1088868306294588$

Leung, A. K.-Y., \& Cohen, D. (2011). Within- and between-culture variation: Individual differences and the cultural logics of honor, face, and dignity cultures. Journal of Personality and Social Psychology, 100, 507-526. Doi: 10.1037/a0022151

Levin, S., Roccas, S., Sidanius, J., \& Pratto, F. (2015). Personal values and intergroup outcomes of concern for group honor. Personality and Individual Differences, 86, 374-384. doi: 10.1016/j.paid.2015.06.047

Lickel, B., Schmader, T., Curtis, M., Scarnier, M., \& Ames, D. R. (2005). Vicarious shame and guilt. Group Processes \& Intergroup Relations, 8, 145-157. doi:10.1177/1368430205051064

Luhtanen, R., \& Crocker, J. (1992). A collective self-esteem scale: Self-evaluation of one’s social identity. Personality and Social Psychology Bulletin, 18, 302-318. doi: $10.1177 / 0146167292183006$

Ma, V. \& Schoeneman, T. J. (1997). Individualism versus collectivism: A comparison of Kenyan and American self-concepts. Basic and Applied Social Psychology, 19, 261273. doi: 10.1207/s15324834basp1902_7

Mackie, D. M., Devos, T., \& Smith, E. R. (2000). Intergroup emotions: Explaining offensive action tendencies in an intergroup context. Journal of Personality and Social Psychology, 79, 602-616. doi:10.1037/0022-3514.79.4.602

Mackie, D. M., Maitner, A. T. \& Smith, E. R. (2015). Intergroup emotions theory. In T.D. Nelson (Ed.), Handbook of Prejudice, Stereotyping, and Discrimination, Vol. 2. (pp. 149-169). New York: Psychology Press. 
Mackie, D. M., \& Smith, E. R. (2015). Intergroup emotions. In J. Dovidio \& J. Simpson (Eds.), APA Handbook of Personality and Social Psychology (Volume II: Interpersonal Relationships and Group Processes). Washington, DC: American Psychological Association.

Mackie, D. M., Smith, E. R., \& Ray, D. G. (2008). Intergroup emotions and intergroup relations. Social and Personality Psychology Compass, 2.5, 1866-1880. doi: 10.1111/j.1751-9004.2008.00130.x

Maitner, A. T. (2015). Emotional Reactions to Unequal Payment: The Impact of Meritocratic Ideology and Salary Negotiability. Group Processes and Intergroup Relations, 18, 153-172. doi: 10.1177/1368430214542255

Miller, D. T. (2001). Disrespect and the experience of injustice. Annual Review of Psychology, 52, 527-553. doi: 10.1146/annurev.psych.52.1.527

Nguyen, A-M. D. \& Benet-Martinez, V. (2007). Biculturalism unpacked: Components, measurement, individual differences, and outcomes. Social and Personality Psychology Compass, 1, 101-114. doi: 10.1111/j.1751-9004.2007.00029.x

Obeidallah, D. (2012, September 20). Media don’t get \#MuslimRage. CNN. Retrieved 09-2013 from http://edition.cnn.com/2012/09/19/opinion/obeidallah-muslimsrage/index.html?hpt=hp_c1

Pitt-Rivers, J. (1965). Honor and social status. In J. G. Peristiany (Ed.), Honor and Shame: The Values of Mediterranean Society (pp. 19-78). London, UK: Weidenfeld and Nicolson.

Qualtrics. (2009).Qualtrics (Version 61959) [Computer Software]. Provo, UT: Qualtrics http://www.qualtrics.com. 
Roccas, S., Savig, L., Schwartz, S., Halevy, N., \& Eidelson, R. (2008). Toward a unifying model of identification with groups: Integrating theoretical perspectives. Personality and Social Psychology Review, 12, 280-306. doi: 10.1177/1088868308319225

Rodriguez Mosquera, P. M., Fischer, A. H., Manstead, A. S. R., \& Zaalberg, R. (2008). Attach, disapproval, or withdrawal? The role of honour in anger and shame responses to being insulted. Cognition and Emotion, 22, 1471-1498, doi:

$10.1080 / 02699930701822272$

Rodriguez Mosquera, P. M., Manstead, A. S. R., \& Fischer, A. H. (2002). The role of honour concerns in emotional reactions to offences. Cognition \& Emotion, 16, 143-163. doi: $10.1080 / 02699930143000167$

Smith, E. R. (1993). Social identity and social emotions: Toward new conceptualizations of prejudice. In D. M. Mackie \& D. L. Hamilton (Eds.), Affect, cognition, and stereotyping: Interactive processes in group perception (pp. 297-315). San Diego: Academic Press.

Smith, E. R., Seger, C. R., \& Mackie, D. M. (2007). Can emotions be truly group level? Evidence regarding four conceptual criteria. Journal of Personality and Social Psychology, 93, 431-446. doi: 10.1037/0022-3514.93.3.431

Stephens, N. M., Fryberg, S. A., Markus, H. R., Johnson, C. S., \& Covarrubias, R. (2012). Unseen disadvantage: How American universities’ focus on independence undermines the academic performance of first-generation college students. Journal of Personality and Social Psychology, 6, 1178-1197. doi: 10.1037/a0027143

Tajfel, H., \& Turner J. C. (1986). The social identity theory of intergroup conflict. In S. Worchel \& W. G. Austin (Eds.), Psychology of intergroup relations (pp. 7-24). Chicago: Nelson-Hall. 
Turner, J. C., Hogg, M. A., Oakes, P. J., Reicher, S. D., \& Wetherell, M. S. (1987).

Rediscovering the social group: A self-categorization theory. Cambridge, MA: Basil Blackwell.

Uskul, A. K., Cross, S. E., Günsoy, C., Gerçek-Swing, B., Alözkan, C., \& Ataca, B. (2015). A price to pay: Turkish and northern American retaliation for threats to personal and family honor. Aggressive Behavior, 41, 594-607. doi: 10.1002/ab.21598

Verkuyten, M., \& Pouliasi, K. (2006). Biculturalism and group identification: The mediating role of identification in cultural frame switching. Journal of Cross-Cultural Psychology, 37, 312- 326. doi: 10.1177/0022022106286926

Yzerbyt, V., Dumont, M., Wigboldus, D., \& Gordijn, E. (2003). I feel for us: The impact of categorization and identification on emotions and action tendencies. British Journal of Social Psychology, 42, 533-549. doi:10.1348/014466603322595266 


\section{Footnotes}

${ }^{1}$ A 4-item scale that included the item "You have to be prepared to fight for your family’s honor.”

${ }^{2}$ A $51^{\text {st }}$ participant, who did not provide responses to the majority of DVs, was excluded from all analyses.

${ }^{3}$ We also measured participants' desire to "respond to the visitor," which was associated with a desire to oppose the visitor for Arab $(r=.45)$ but not British $(r=-.08)$ participants. To ensure comparability, we focused on the more aggressive of the two options.

${ }^{4}$ Although it can be difficult to directly compare means obtained in different cultural contexts, we argue that the invariance found on the dependent variables in the control condition suggests that there were no systematic differences in the way Arab and British participants used scales.

${ }^{5}$ We also investigated whether endorsement of honor norms interacted with culture and insult to influence participants' anger responses. In fact, we would expect that for Arab participants, the more they endorse honor norms, the more anger they would feel in response to insult. This three-way interaction was not significant $(\Delta R 2=.002, F(1,92)=.35, p=$ .555). We think this is largely due to the fact that the measure of honor was highly skewed for Arab participants (the mode is '6,' which is the ceiling of the scale), thus lowering statistical power due to the limited variance in this measure.

${ }^{6}$ We would typically report bivariate correlations among honor endorsement, identification, evaluations of insult, emotions, and behaviors in this and the following two studies. However, because evaluations of insult, emotions, and behaviors were affected by manipulations, predicted correlations among those variables may be spuriously inflated. Because honor endorsement showed a ceiling effect in Arabs in this study, correlations with 
that variable are likewise uninformative. Thus we thus do not report bivariate correlations here, however correlation tables are available upon request.

${ }^{7}$ To verify that Arab participants do indeed endorse honor norms more than American participants, we collected data from both participant populations. Eight-hundred-twenty-six Americans studying at UCSB (all participants were born in the U.S.; 299 male, 527 female, 2 unknown; $M$ age $=18.87, S D=1.64)$ and 178 participants with an Arab nationality studying at AUS (70 male, 108 female, $M$ age $=19.84, S D=1.61$ ) completed the same 5-item honor scale used in Study 1 (1=Strongly Disagree, 7=Strongly Agree). Analysis revealed that Arab participants $(M=5.97, S D=1.10)$ did indeed report higher honor concerns than did American participants $(M=5.33, S D=0.88), F(1,988)=71.62, p<.001, \eta_{\mathrm{p}}{ }^{2}=.068$. Honor concerns were not affected by Gender, $F(1,988)=2.58, p=.108, \eta_{\mathrm{p}}^{2}=.003$, or the Gender $\times$ Culture interaction, $F(1,988)=0.65, p=.421, \eta_{\mathrm{p}}{ }^{2}=.001$. Further analysis of scores revealed a strong ceiling effect in the Arab data $(s k=-2.07)$ but a more symmetrically distributed dataset in American participants (sk = -.49), suggesting a higher proportion of Arab participants scoring at the very top end of the scale.

${ }^{8}$ Participants also reported attributions and general evaluations of the letter, before responding to the 2 personal honor items administered in Study 1 (i.e., "It is important to me that others see me as someone who deserves respect"; for Arabs, $r=.59, M=6.22$, $S D=1.03$, this variable was not affected by insult condition, $p=.426, \eta_{\mathrm{p}}{ }^{2}=.014$ ), as well as 4 items assessing dignity concerns (i.e. "How others treat me is irrelevant to my worth as a person”; for Arabs, $\alpha=.60, M=4.27, S D=1.23$, this variable was not affected by insult condition, $p=$ $.489, \eta_{\mathrm{p}}^{2}=.011$ ). Unfortunately a programming glitch provided only the first five (of seven) response options (1=Not at all important to 5=Somewhat important) to American participants, and therefore the data are not analyzable for the American sample. Honor endorsement was unrelated to student identification $(r=-.03, p=.784)$ in the Arab sample. 
${ }^{9}$ Seven participants who did not indicate Arab ethnicity were a priori excluded, and are not reported in the total number of participants or elsewhere. 
Table 1. Means and standard deviations for appraisals, emotions, and behaviors by culture and insult condition, Study 1.

\begin{tabular}{lcccc}
\hline & Control & Insult & Control & Insult \\
& & & & \\
\hline Perceptions of & $M=3.70$ & $M=2.54$ & $M=3.50$ & $M=2.42$ \\
& $S D=1.16$ & $S D=1.16$ & $S D=1.10$ & $S D=0.72$ \\
\hline Harm & & & \\
& $M=2.19$ & $M=3.50$ & $M=2.07$ & $M=3.09$ \\
& $S D=1.01$ & $S D=0.98$ & $S D=0.79$ & $S D=0.83$ \\
\hline Justice & $M=4.30$ & $M=2.95$ & $M=4.32$ & $M=4.07$ \\
& $S D=1.23$ & $S D=0.82$ & $S D=0.73$ & $S D=1.01$ \\
\hline Anger & $M=1.57$ & $M=3.16$ & $M=1.37$ & $M=1.96$ \\
& $S D=0.95$ & $S D=1.40$ & $S D=0.48$ & $S D=0.80$ \\
\hline Felt Respect & $M=4.24$ & $M=3.35$ & $M=3.33$ & $M=3.38$ \\
& $S D=1.11$ & $S D=1.04$ & $S D=0.99$ & $S D=0.88$ \\
\hline Anxiety & $M=2.48$ & $M=2.94$ & $M=2.16$ & $M=2.64$ \\
& $S D=1.03$ & $S D=1.18$ & $S D=0.70$ & $S D=0.94$ \\
\hline Oppose & & & \\
& $M=2.38$ & $M=3.84$ & $M=2.16$ & $M=2.20$ \\
& $S D=1.66$ & $S D=1.95$ & $S D=1.21$ & $S D=1.32$ \\
\hline Avoid & & & \\
\hline & $M=1.27$ & $M=1.82$ & $M=1.50$ & $M=1.90$ \\
& $S D=0.68$ & $S D=1.06$ & $S D=0.71$ & $S D=0.85$ \\
& & & \\
\hline
\end{tabular}


Table 2. Means and standard deviations for appraisals and emotions by culture and insult condition, Study 2.

\begin{tabular}{lcccccc}
\hline & Control & $\begin{array}{c}\text { Honor } \\
\text { Insult }\end{array}$ & $\begin{array}{c}\text { Dignity } \\
\text { Insult }\end{array}$ & Control & $\begin{array}{c}\text { Honor } \\
\text { Insult }\end{array}$ & $\begin{array}{c}\text { Dignity } \\
\text { Insult }\end{array}$ \\
\hline $\begin{array}{l}\text { Perceptions } \\
\text { of being } \\
\text { respected }\end{array}$ & $M=4.13$ & $M=3.09$ & $M=3.49$ & $M=3.51$ & $M=2.88$ & $M=3.34$ \\
\hline Harm & $M=1.36$ & $S D=1.39$ & $S D=1.54$ & $S D=1.24$ & $S D=1.44$ & $S D=1.55$ \\
& & & & & & \\
\hline Justice & $S D=1.50$ & $S D=1.47$ & $S D=1.45$ & $S D=1.43$ & $S D=1.49$ & $S D=1.46$ \\
& $M=5.17$ & $M=4.29$ & $M=4.42$ & $M=5.04$ & $M=4.28$ & $M=4.74$ \\
& $S D=1.31$ & $S D=1.47$ & $S D=1.48$ & $S D=1.33$ & $S D=1.22$ & $S D=1.43$ \\
& & & & & & \\
\hline Anger & $M=3.31$ & $M=4.42$ & $M=4.10$ & $M=3.53$ & $M=4.15$ & $M=3.81$ \\
& $S D=1.52$ & $S D=1.45$ & $S D=1.48$ & $S D=1.29$ & $S D=1.45$ & $S D=1.42$ \\
& & & & & & \\
\hline Felt Respect & $M=3.65$ & $M=3.32$ & $M=3.18$ & $M=3.21$ & $M=2.35$ & $M=2.40$ \\
& $S D=1.35$ & $S D=1.48$ & $S D=1.69$ & $S D=1.40$ & $S D=1.39$ & $S D=1.53$ \\
& & & & & & \\
\hline Shame & $M=3.66$ & $M=3.84$ & $M=3.67$ & $M=3.94$ & $M=3.73$ & $M=3.63$ \\
& $S D=1.58$ & $S D=1.65$ & $S D=1.76$ & $S D=1.50$ & $S D=1.41$ & $S D=1.69$ \\
& & & & & & \\
\hline
\end{tabular}


Table 3. Means and standard deviations for manipulation checks, appraisals, emotions, and behaviors by identity and insult condition, Study 3.

\begin{tabular}{|c|c|c|c|c|}
\hline & Public & Private & Public & Private \\
\hline Public & $\begin{array}{l}M=4.65 \\
S D=1.14\end{array}$ & $\begin{array}{c}M=3.81 \\
S D=1.33\end{array}$ & $\begin{array}{c}M=4.24 \\
S D=1.41\end{array}$ & $\begin{array}{c}M=3.73 \\
S D=1.48\end{array}$ \\
\hline Insult & $\begin{array}{l}M=3.95 \\
S D=1.25\end{array}$ & $\begin{array}{c}M=3.93 \\
S D=1.25\end{array}$ & $\begin{array}{c}M=3.23 \\
S D=1.29\end{array}$ & $\begin{array}{c}M=3.64 \\
S D=1.47\end{array}$ \\
\hline $\begin{array}{l}\text { Perceptions of } \\
\text { being respected }\end{array}$ & $\begin{array}{l}M=4.00 \\
S D=1.24\end{array}$ & $\begin{array}{c}M=3.84 \\
S D=1.31\end{array}$ & $\begin{array}{l}M=4.25 \\
S D=1.08\end{array}$ & $\begin{array}{l}M=3.92 \\
S D=1.31\end{array}$ \\
\hline Harm & $\begin{array}{l}M=3.78 \\
S D=1.20\end{array}$ & $\begin{array}{l}M=3.79 \\
S D=1.28\end{array}$ & $\begin{array}{l}M=3.59 \\
S D=1.26\end{array}$ & $\begin{array}{c}M=3.72 \\
S D=1.22\end{array}$ \\
\hline $\begin{array}{l}\text { Justice } \\
\end{array}$ & $\begin{array}{l}M=4.28 \\
S D=1.13\end{array}$ & $\begin{array}{l}M=4.18 \\
S D=1.08\end{array}$ & $\begin{array}{l}M=4.33 \\
S D=0.83\end{array}$ & $\begin{array}{c}M=4.09 \\
S D=1.14\end{array}$ \\
\hline Anger & $\begin{array}{l}M=3.59 \\
S D=1.73\end{array}$ & $\begin{array}{c}M=3.61 \\
S D=1.56\end{array}$ & $\begin{array}{c}M=2.41 \\
S D=1.54\end{array}$ & $\begin{array}{c}M=2.62 \\
S D=1.43\end{array}$ \\
\hline Felt Respect & $\begin{array}{l}M=3.35 \\
S D=1.21\end{array}$ & $\begin{array}{c}M=3.22 \\
S D=1.25\end{array}$ & $\begin{array}{c}M=3.39 \\
S D=1.29\end{array}$ & $\begin{array}{c}M=3.63 \\
S D=1.30\end{array}$ \\
\hline Shame & $\begin{array}{l}M=3.57 \\
S D=1.68\end{array}$ & $\begin{array}{l}M=2.98 \\
S D=1.56\end{array}$ & $\begin{array}{c}M=2.39 \\
S D=1.50\end{array}$ & $\begin{array}{l}M=2.68 \\
S D=1.58\end{array}$ \\
\hline Anxiety & $\begin{array}{l}M=3.73 \\
S D=1.58\end{array}$ & $\begin{array}{c}M=3.13 \\
S D=1.48\end{array}$ & $\begin{array}{c}M=2.94 \\
S D=1.68\end{array}$ & $\begin{array}{c}M=2.69 \\
S D=1.42\end{array}$ \\
\hline Pride & $\begin{array}{l}M=3.11 \\
S D=1.53\end{array}$ & $\begin{array}{c}M=3.08 \\
S D=1.51\end{array}$ & $\begin{array}{c}M=2.92 \\
S D=1.55\end{array}$ & $\begin{array}{l}M=3.33 \\
S D=1.53\end{array}$ \\
\hline Confront & $\begin{array}{l}M=3.36 \\
S D=1.67\end{array}$ & $\begin{array}{c}M=3.43 \\
S D=1.64\end{array}$ & $\begin{array}{c}M=2.90 \\
S D=1.72\end{array}$ & $\begin{array}{c}M=3.11 \\
S D=1.71\end{array}$ \\
\hline Criticize & $\begin{array}{c}M=3.12 \\
S D=1.66\end{array}$ & $\begin{array}{c}M=3.03 \\
S D=1.64\end{array}$ & $\begin{array}{c}M=2.93 \\
S D=1.72\end{array}$ & $\begin{array}{c}M=2.94 \\
S D=1.71\end{array}$ \\
\hline Shaming & $\begin{array}{l}M=2.89 \\
S D=1.69\end{array}$ & $\begin{array}{l}M=2.54 \\
S D=1.43\end{array}$ & $\begin{array}{c}M=2.42 \\
S D=1.68\end{array}$ & $\begin{array}{l}M=2.75 \\
S D=1.96\end{array}$ \\
\hline Defending & $\begin{array}{l}M=4.05 \\
S D=1.92\end{array}$ & $\begin{array}{c}M=4.24 \\
S D=2.00\end{array}$ & $\begin{array}{c}M=3.58 \\
S D=1.90\end{array}$ & $\begin{array}{c}M=3.67 \\
S D=1.88\end{array}$ \\
\hline
\end{tabular}

